DIGITALCOMMONS

@WAYNESTATE -
Michigan Journal of Counseling:

Research, Theory and Practice

Volume 37 | Issue 2

Article 4

$12-1-2010$

\title{
Increasing Self-Empowerment related to Depression among Court-Involved Youth: The Moods Matter Project
}

Nancy G. Calley

University of Detroit Mercy, calleyng@udmercy.edu

Lisa D. Hawley

Oakland University, hawley@oakland.edu

Follow this and additional works at: https://digitalcommons.wayne.edu/mijoc

\section{Recommended Citation}

Calley, N. G., \& Hawley, L. D. (2010). Increasing Self-Empowerment related to Depression among Court-Involved Youth: The Moods Matter Project, Michigan Journal of Counseling, 37(2), 18-30. doi:10.22237/mijoc/1291161780

This Article is brought to you for free and open access by the Open Access Journals at DigitalCommons@WayneState. It has been accepted for inclusion in Michigan Journal of Counseling: Research, Theory and Practice by an authorized editor of DigitalCommons@WayneState. 


\section{Increasing Self-Empowerment related to Depression among Court- Involved Youth: The Moods Matter Project}

\section{Cover Page Footnote}

Funding for this study was jointly provided by Blue Cross Blue Shield of Michigan and Spectrum Human Services, Inc. \& Affiliated Companies, and both organizations have the authors' appreciation for this support. Inquiries regarding this article should be directed to Nancy G. Calley, Associate Professor and Chair, Department of Counseling and Addiction Studies, University of Detroit Mercy, calleyng@udmercy.edu. 
Increasing Self-Empowerment related to Depression among Court-

\section{Involved Youth: The Moods Matter Project}

Nancy G. Calley

University of Detroit Mercy

Lisa D. Hawley

Oakland University

\section{Abstract}

An empirically-guided program designed to empower at-risk youth through increased knowledge of depression and prevention resources was developed and implemented. Ninety-three court-involved adolescents participated in the Moods Matter project, a four-part psycho-educational group experience rooted in the principles of Rational Emotive Behavior Therapy (REBT). Addressing the disproportionate incidence of depression among court-involved youth and the need for short-term interventions that promote self-empowerment, the program was developed specifically for court-involved youth in out of home placement. The results of this exploratory pilot study found significant gains among participants related to increased knowledge of depression. Additionally, all participants successfully completed an individualized safety plan following the intervention.

\section{Increasing Self-Empowerment related to Depression among Court- Involved Youth: The Moods Matter Project}

One of the most prevalent and serious mental health disorders among adolescents is depression. In fact, the 2004 National Survey on Drug Use and Health estimated the lifetime prevalence rate of depression among adolescents at $14 \%$ (Office of Applied Studies, Substance Abuse and Mental Health Services Administration, 2005). Three to eight percent of adolescents are diagnosed with Major Depressive Disorder making it more common among this age group than other chronic childhood disorder, including asthma (Jackson \& Lurie, 2006). Since adolescent depression does not typically occur in isolation, depressed adolescents are at greater risk of co-morbid issues such as substance abuse, educational challenges, problems with social relationships, and conduct

Nancy G. Calley, Ph.D., LPC is an Associate Professor and Chair of the Department of Counseling and Addiction Studies at the University of Detroit Mercy. She can be reached at: calleyng@udmercy.edu. Lisa D Hawley, Ph.D., LPC is an Associate Professor and Chair of the Department of Counseling at Oakland University. She can be reached at: hawley@oakland.edu. 
disorders (Zalsman, Brent, \& Weersing, 2006). Moreover, suicide, a byproduct of depression, is the third leading cause of death among individuals 15-24 years of age in the United States (Kochanek, Murphy, Anderson, \& Scott, 2004). For court-involved youth, the prevalence of depression and other mental health disorders is even greater. In fact, approximately $40-85 \%$ of children within the child welfare system suffer from one or more mental health disorders (Austin, 2005 ) and between $65-70 \%$ of youth in the juvenile justice system meet the criteria for a mental health disorder (Skowyra \& Cocozza, 2006) including depression.

The disproportionate incidence of depression among court-involved youth indicates the need for specific interventions designed to meet the needs of this special population. However, whereas several evidence-based practices to prevent depression have been developed in recent years (Garber, Clarke, \& Weersing, 2009; Gillham, Reivich, Jaycox, Seligman, \& Silver, 1990; Mufson, et al.,2004; Spence, Sheffield, \& Donovan, 2005 ), none have been designed to specifically address the unique needs of court-involved youth. Namely, studies must be designed to address needs related to adolescents with limited, if any, social and family supports, and challenges related to the brief periods of time available to intervene with this population. In response to these needs, the Moods Matter project, a brief cognitive behaviorally-based group intervention was designed to increase knowledge and resources related to depression to promote self-sufficiency and empowerment.

\section{Literature Review}

\section{Depression among Court-Involved Youth}

The increased risk for depression associated with court-involved adolescents is often due to exposure to early trauma (Birhmaher, et al., 2001). In fact, Garber and Flynn (2001) found that individuals with a history of child maltreatment might adopt a negatively skewed cognitive style as a result of the experience of early trauma. As a result, these individuals may possess a cognitive schema that tends to interpret events in a manner that promotes self-blame and negativity, and a sense that the glass is half empty rather than half full. This endorsement of such a negatively skewed cognitive style is thought to contribute to the risk of subsequent depression.

Furthermore, this type of environmental conditioning or sensitization to depression appears to place individuals that were exposed to adversity at an early age at disproportionate risk for chronic depression following life challenges of varying degrees (Monroe \& Harkness, 2005; Harkness, Bruce, \& Lumley, 2006). As a result, these individuals may be conditioned to continuously interpret events, regardless of their realistic severity, as overwhelming, and thus, experience feelings of helplessness that further contribute to their depression. Additionally, individuals with a history of child maltreatment may experience shorter times of wellness in between depressive episodes (Harkness, et. al., 2006). Thus, the chronic nature of depression compounded by only brief reprieves experienced by these individuals may place them at significant risk of sustaining adequate functional ability, and living healthy, full lives. Conversely, 
chronic depression may place these individuals at significant risk of engaging in self-harmful behaviors, including suicide.

\section{Depression Prevention Programs for At-Risk Youth}

The majority of adolescent depression prevention programs that have been developed over the past several years have used psycho-educational approaches most often based in cognitive-behavioral therapy (Garber, Clarke, \& Weersing, 2009; Gillham, Reivich, Jaycox, Seligman, \& Silver, 1990; Spence, Sheffield, \& Donovan, 2005; Vernon, 2006). One exception to this, however, is the interpersonal psychotherapy (ITP) model (Mufson, et al., 2004). This approach uses psycho-education to increase knowledge related to depression and prevention, and skill-building techniques to address interpersonal deficits, role conflicts and role transition. In a school-based program using ITP, the intervention was comprised of two initial individual sessions followed by eight weekly group sessions. Initial evaluation of the program by the developers supported the efficacy of the approach in reducing depressive symptoms (Mufson, Dorta, \& Wickramarante, 2004) and a more recent study examined the program's preventative effects on depression (Young, Mufson, \& Davies, 2006). In this recent study, 41 mostly Hispanic youth, aged 11-16 years, with elevated scores of depressive symptoms were randomly assigned to either the ITP treatment or to a school counseling control group. At six month follow-up, significant improvement was found in the ITP group vs. the control group with the ITP group participants demonstrating a significant reduction in depressive symptoms at six month follow-up.

The Problem-Solving for Life program (PSFL) is another school-based approach and one that is based upon cognitive behavioral therapy. The PSFL was delivered to 12 to 14 year old adolescents in Australia (Spence, Sheffield, \& Donovan, 2005), with the intervention consisting of eight 45-50 minute weekly sessions focused on problem-solving and cognitive restructuring. In one of the largest studies to date, 1,500 youth were assigned to either the cognitivebehavioral treatment group or the no intervention control group. There were no significant differences found between students that completed the preventive intervention compared with those who did not from pre-intervention to four year follow up.

The Penn Resiliency Program (PRP; Gillham, Reivich, Jaycox, Seligman, \& Silver, 1990), one of the longest used depression programs is another school-based cognitive-behavioral program. PRP consists twelve $90-120 \mathrm{mi}-$ nute group sessions in which adolescents are taught the connection between life events, their interpretations of those events and the related emotional consequences. PRP has been evaluated several times over the past two decades with overall findings that adolescents participating in the program report fewer depressive symptoms than those in the control group following the intervention (Gillham, Brunwasser, \& Freres, 2008). In a study evaluating the effectiveness of PRP in preventing clinical episodes of depression in those with elevated symptoms of depression (Gillham, Hamilton, Freres, Patton, \& Gallop, 2006), self-reported high-risk 11 and 12 year old children participated in the PRP or 
control group. Females in the PRP treatment group demonstrated a significantly greater reduction in depressive symptoms than females and males in the control group.

One multi-site study examined the effectiveness of a cognitive behavioral (CB) prevention program for depression in adolescents with a high familial and individual risk (Garber, Clarke, \& Weersing, 2009). This study involved 316 youth ranging in age from $13-17$ years, $58 \%$ of whom were female and approximately $25 \%$ of whom identified as an ethnic/racial minority. Youth were randomized to receive either usual care or a six month $\mathrm{CB}$ treatment that involved eight weekly sessions and six monthly continuation group sessions. Results revealed significant differences between the groups with the CB group demonstrating an $11 \%$ lower rate of depressive episodes than the usual care group.

Common to the majority of existing depression prevention programs is the use of cognitive-behavioral theory and a curriculum-based model. In addition, all of the programs have been relatively brief ranging from three to six months in duration, and several programs have been school-based. However, although there has been a modest number of depression prevention programs developed recently for youth, little attention has been given to depression prevention programs for youth of various ethnic and racial backgrounds (Gladstone \& Beardslee, 2009). Unfortunately, there is also an absence of programs designed specifically for court-involved adolescents residing in temporary and independent living placements-perhaps one of the highest risk populations and one that requires short-term intervention to address the often limited time professionals have to intervene.

In order to address the strengths (i.e., cognitive-behavioral therapy, curriculum-based model, group interventions), weaknesses (i.e., limited long-term effects of preventing depression), and gaps (i.e., interventions that are effective across ethnic and racial groups, different intervention delivery settings) in the existing research on depression prevention programs, the Moods Matter project was conceived. In addition, the program was designed as a short-term secondary prevention program to reduce depression and promote self-empowerment among court-involved youth in temporary or short-term placements-a targeted high-risk special population. To address these issues, the Moods Matter program used a curriculum-based group approach based upon a model of cognitive-behavioral therapy--Rational Emotive Behavior Therapy (REBT) (Ellis, 2000). To address the challenge of limited time to intervene with this population, it was believed that the focus of prevention should be primarily focused on self-empowerment. In this context, self-empowerment referred to increasing knowledge and resources related to depression among project participants, thus providing participants with the tools needed for future self-care. This type of intervention was guided by the fact that court-involved youth typically have significantly fewer family and social supports than their non-court-involved peers, and was consistent with increased self-sufficiency that is emphasized throughout the child welfare and juvenile justice systems (CWLA, 2005). Further, promoting self-empowerment is consistent with cognitive-behavioral ap- 
proaches. To reflect this focus on self-empowerment, the program was designed to increase basic knowledge of depression, introduce self-management skills, and promote the development of individualized safety plans to address future depression.

Because of the inherent barriers to conducting randomized clinical trials with court-involved youth and previous mixed results related to depression prevention programs, this study was exploratory. In the exploratory phase of the study, acquisition of knowledge of depression and ability to develop an adequate safety plan were evaluated.

\section{Methods}

\section{Participants}

\section{Youth.}

Ninety-three youth ages $12-20$ years participated in the Moods Matter project with 16 and 17 year olds comprising $57 \%$ of the total. Sixty-four percent of the participants were male while $31.2 \%$ were female. With regard to racial and ethnic backgrounds of participants, $78.5 \%$ were Black and all youth identified as Black were African American while $12.9 \%$ identified as White and of various ethnicities, including Arab-American, European-American, and Latino. At the time of the project, all of the participants were court-involved in the child welfare or juvenile justice system, and in temporary placements such as semiindependent living, short-term residential care, or at home receiving short-term community-based services. The youth were all receiving services from one private, non-profit human service organization in a multi-county region in a Midwestern state. Of the ninety percent of youth providing placement information, $32 \%$ were residing in a residential facility, $37 \%$ were participating in a semiindependent living program, and $21 \%$ were receiving community-based services. Pre-intervention participant scores on the Beck Depression Inventory II were in the following ranges: $11 \%(n=10)$ - severe depression, $16 \%(n=15)$ moderate to severe depression, $16 \%(n=15)$ - mild to moderate depression, and $57 \%(n=53)-$ normal. This finding was consistent with previous data indicating $40 \%$ or greater prevalence of depression among court-involved youth (Austin, 2005; Skowyra \& Cocozza, 2006).

To recruit volunteers, all clients in each of the programs were asked to participate. Project facilitators informed youth and parents/legal guardians that participation in the project was completely voluntary, and reviewed informed consent forms identifying risks and benefits with each. One hundred participants volunteered, however, seven $(7 \%)$ of the initial participants did not complete all four sessions, and were therefore, not included in the results.

\section{Project facilitators.}

The project facilitators were clinicians working within the organization with youth in child welfare and juvenile justice programs. All of the clinicians had Master's degrees in Counseling, Psychology, or Social Work and held state licensure. The clinicians were trained as Project Facilitators and were provided 
all of the materials to facilitate the project independently. Training of the group facilitators involved: an orientation to the objectives of the project, review of the Moods Matter curriculum, instruction in the role of the group facilitator, and the use of brainstorming and debriefing activities as critical to increasing group member self-exploration and promoting interpersonal feedback.

\section{Instruments}

Two outcome measures were used to gather initial data on increased knowledge related to depression and the development of an individualized Safety Plan. The Assessment of Knowledge Related to Adolescent Depression, a fifteen-item questionnaire consisting of True and False items was developed by the first author to assess basic knowledge of depression. The questionnaire was administered before and following the intervention. The instrument consisted of material covered in the Moods Matter sessions, all of which was drawn directly from current research on depression, mood management, and REBT.

The second outcome measure involved completion of an individual Safety Plan. The Safety Plan was the culminating activity of the Moods Matter project, a focused plan to aid youth in future depression through selfmanagement tools and accessing needed resources.

The Moods Matter program consisted of four psycho-educational group sessions. The curriculum was designed to be delivered in four sessions over a one-month period, and the group-based curriculum consisted of the following major components: 1) Understanding your Emotional Self: Moods and Behaviors, 2) Why Moods Matter: Risks and Consequences, 3) Taking Control of Moods: Assessment, Empowerment, Advocacy, and Treatment, and 4) Safety Planning. The curriculum consisted of instructional tools that included brief lecture material and video clips interspersed with group-based exercises founded in REBT that were completed by the group throughout the sessions. As the project was designed to promote future self-empowerment, a curriculum booklet was provided to each participant with several sets of additional exercises and instructions for continued independent use of the materials following completion of the group. Additionally, each participant received a wallet-sized information card with telephone numbers for various public health and safety organizations, a reading list of books specifically related to depression and teens, and a Depression Checklist, identifying various signs and symptoms of depression. Successful completion of the program was evidenced by participation in all four sessions and completion of an individualized Safety Plan that each youth retained following the program.

Ten groups of 6-12 youth participated in the Moods Matter project with group composition based upon program placement (i.e., community-based, residential treatment, independent living). The groups took place in either a residential setting for youth in residential treatment or in a community-based site for youth in community-based placement (i.e., home, semi-independent living). All group sessions occurred during a one-month period and consisted of four two- 
Immediately prior to beginning the group sessions, the group facilitator provided instructions to all group members about each of the pre-group assessment activities, including information regarding privacy protections, purpose of the data, and participants' right to refuse completion of any of the documents. Additionally, participants were informed that the results of the depression screening would be reviewed with each of them privately by their therapist (i.e., the group facilitator) during their next scheduled therapy session. After responding to any participant questions, the pre-group assessment materials were distributed to participants for completion (i.e., demographic information, depression screening, pretest).

Each of the four sequential psycho-education sessions was similar in structure, consisting of brief lecture material aided by the use of Powerpoint slides. Each slide presentation was brief (i.e., less than 10 minutes) and was followed by a related group exercise (the amount of time allocated for each slide presentation was limited in consideration of participant developmental level). Following each group exercise, the facilitator led short debriefings to allow time for participants to further process the exercise, reflecting on learning that occurred and engaging in further discussion about issues addressed in the exercise.

\section{Session one.}

The initial session began with a brief primer regarding the interrelationships between cognitions, emotions and behaviors, establishing the framework for developing an understanding of Rational Emotive Behavior Therapy. This discussion emphasized the effect that events or actions may have on feelings as well as the effect that feelings may have on actions or behaviors. Following completion of the group exercises, the A- B- C model (Ellis, 2000) was presented and discussed. The group then engaged in an ABC model exercise, identifying personal activating events (e.g., failed a test), faulty beliefs constructed as a result of the event (e.g., I am stupid) and the subsequent emotional consequence (e.g., I feel down).

Emphasizing the power of cognitions in emotional consequences, personal language and self-talk was discussed, paying particular attention to the manner in which each can be inflexible and rigid and as a result, can further contribute to creating emotional difficulty. An extreme vocabulary exercise was used in which group members identified words and messages used as part of self-talk that are rigid or inflexible (e.g., always, has to). As an adjunctive exercise, group members were then asked to identify personal extreme messages (i.e., my life will always be bad). The group further discussed the effects that extreme language has had on the clients' affect and behaviors, and ultimately, discussed the role that such language may have on self-esteem and selfefficacy. The initial session was designed to accomplish several objectives that included the following: educate group participants about the complex relationships between thoughts, feelings, and behaviors, explore personal thinking, feeling and behavior patterns to increase self-awareness, and examine the im- 
pact of cognition on self-efficacy. As such, the initial session provided the first potential steps toward prevention and management of depression through increased awareness and knowledge about cognitions, affect and behavior, and the power of thinking patterns to influence feelings and behaviors.

\section{Session two.}

Continuing to use Ellis' (2000) ABC model, the D-E-F portion was presented and discussed. Because the Moods Matter project was designed for adolescents, the $F$ was modified to reflect a more fun, less stressful way of living arising from the adoption of a new, effective philosophy. Using the group's original $A B C$ exercise, the group disputed the original beliefs by replacing each with more flexible, rational thoughts and identifying subsequent feelings that would likely emerge as a result of this new way of thinking (e.g., it's all right if she doesn't like me, I'm OK).

As a means of effectively transitioning between more weighty topics (i.e., rational vs. irrational thoughts to understanding depression) and in order to introduce a wellness-inspired focus to examining the relationship between moods, thoughts and behaviors, a discussion of Favorite Things was facilitated. Participants explored their favorite activities and the resulting thoughts and feelings experienced following participation in such activities. Taking this a step further, group members also identified activities that they would like to do but have not yet tried, and finally, group members were asked to identify a time when they could plan to try one or more of the new activities. To ensure the feasibility of each activity, group members were instructed to only identify activities that they could engage in currently and independently, thereby ensuring that the activities were indeed feasible. This type of exercise was viewed as particularly meaningful with this population because so often the experience of being court-involved is one largely marked by loss, either temporary or permanent (e.g., related to degree of freedom, home, family, community, possessions). More significantly, this exercise was designed to potentially prevent depression and manage depression for those experiencing depression. As such, participants were guided to explore ways by which they could engage in meaningful activities and seek out new meaningful activities, thus challenging any possible negative outlook that viewed life as lacking or without meaning or change.

\section{Session three.}

The third session, Why Moods Matter: Risks and Consequences, focused on increasing understanding of depression through an examination of depression, risk factors, and treatment. The session began with an examination of the clinical symptoms of a depressive episode, as identified in the Diagnostic and Statistical Manual of Mental Health Disorders - TR (American Psychiatric Association, 2000), with an emphasis on the role of development in symptom presentation (i.e., depressed mood in adults vs. irritable mood in children and adolescents). The various risk factors for depression were then explored, with specific attention paid to teens and to the unique differences related to the experience of court-involved teens (e.g., not living with parent(s), changing 
schools). In order to increase awareness of the burden of depression on an individual, the group then engaged in a brainstorming activity to identify the various costs---including but not limited to, emotional (e.g., friends), achievement (e.g., school), financial (e.g., work) associated with suffering from depression.

Next, methods by which to receive help for depression were discussed. The role of peers, teachers, case workers, caregivers, and other support persons in assisting individuals in seeking professional assistance were discussed as were the various types of professionals that are trained to treat depression. Additionally, the group counselor facilitated a discussion about methods by which to access professional help (i.e., informational cards, telephone, location of local clinics). Finally, the role of medication was briefly discussed as a potential form of treatment, when justified.

\section{Session four.}

In the final session, group members worked together to develop a Safety Plan brainstorming all of the necessary components. To build the Safety Plan, group members identified individuals that cared about them with whom they could talk, individuals that could monitor them when feeling down, professionals from whom they could seek help, types of activities that had helped them previously when feeling down, methods by which they could assess the role that personal thoughts and beliefs could be having on mood, as well as other issues related to self-monitoring and accessing help. Following the development of the group Safety Plan, participants developed individual Safety Plans. Because the intervention was group-based, the authors believed by having participants first engage in brain-storming the necessary aspects of a Safety Plan, that each participant would be better prepared to develop his/her individual Safety Plan.

Teaching participants about the various forms of treatment available and methods by which to access help for depression, as well as guiding participants in the development of their own action plans to address depression, were each designed to promote self-management and self-empowerment, significant in both primary and secondary prevention of depression. Following the final session of the project, participants completed the post-test regarding knowledge of depression.

\section{Results}

An independent t-Test was completed between the pre-test $(n=93)$ and post-test scores $(n=90)$ to compare project learning outcomes. The $t$ test comparing the mean pre-test questionnaire responses $(M=9.69, S D=2.36)$ with that of the post-test questionnaire responses $(M=11.36, S D=2.53)$ was significant, $t$ $(181)=4.578, p<. .05$, indicating gains in knowledge gained from pre- to posttest. The composition of the groups varied in type of juvenile justice or child welfare program, gender, age, and race. No significant differences were found on the pre-post test scores related to participant program, gender, age, or race.

All 93 participants successfully completed an individualized Safety Plan. Because the Safety Plan was designed to assist participants in identifying po- 
tential supports that could be accessed in the future, successful completion of the Safety Plan was defined as the completion of the Safety Plan including the identification of at least two supportive individuals and three community resources.

\section{Discussion}

The results of the pre-post test indicate that significant gains in knowledge related to depression were achieved. Providing information and increasing knowledge related to depression is considered the initial step in both primary and secondary prevention of depression, and as such, is essential to any clinical intervention with depression.

Whereas the knowledge related to depression provided one measure of impact, the development of individualized Safety Plans provided evidence that participants were able to identify specific individuals and resources available to them for support. This was viewed as a critical step toward self-empowerment. As a result, the increased knowledge and awareness of depression coupled with the completion of personal Safety Plans could indeed indicate increased ability to acknowledge future depression, and to access help for depression.

To fully interpret the findings of this study, it is important to note its strengths and weaknesses. Its strengths included an effective sample size, the inclusion of ethnic and racial minorities in the sample, and the inclusion of courtinvolved youth in the sample. The inclusion of these groups addressed significant gaps in the literature. Moreover, because of the prevalence of depression among court-involved youth, specifically targeting this population served as a first step to exploring potential methods for addressing depression. In addition, because of the often transient nature of court-involved youth, this type of brief and affordable approach may be particularly attractive. In fact, without continued work to address depression among this population, youth that are already marginalized as a result of their court-involved status, may face additional marginalization as a result of their clinical needs not being effectively addressed.

\section{Limitations of the Study}

Although the results of the short-term outcomes were well worth reporting and reflect the need for practice-informed research, there were significant limitations to the study that included the lack of a psychometrically sound instrument and the lack of a control group. Both of these limitations will need to be addressed in future studies. However, the ethical obligation regarding withholding treatment from a high-risk youth population will need to be addressed in a control group design.

Because the Moods Matter curriculum was based upon current research and the pre-posttest items were drawn directly from the curriculum, the pre-posttest was empirically-guided. However, these results must be interpreted with caution since an existing measure with established psychometric properties was not available for use. Finally, because this project emphasized the use of a brief self-empowerment intervention to high risk youth that often are unable to both participate in long-term interventions and follow-up, the long-term impact of 
the intervention is not known.

\section{Implications for Future Research}

This study serves as an initial step in addressing depression among high-risk youth through the provision of a brief self-empowerment program. Further, it reinforces the need for continued efforts to design prevention and treatment interventions that can be implemented despite the logistical challenges inherent among these populations (i.e., length of time in care, cost). Whereas the initial project objectives were met, the results of the project indicate the need for further work in this area to more rigorously evaluate the program's efficacy. This would entail the use of an additional pre-posttest outcome measure to assess increased knowledge, the use of a randomized clinical trial, and longterm follow-up to assess long-term gains in knowledge and application of skills.

In addition, regardless of the challenges inherent in practice research, clinicians must continue to engage in this type of research as it has not only scholarly implications, but more importantly, it serves to immediately address existing societal needs, often among marginalized populations and within reallife contexts. Therefore, rather than relying on school-based research or other youth populations that may prove easier to access, greater efforts should be made to involve specific sub-populations of high-risk youth. Doing so can ensure that effective interventions continue to be designed to meet the needs of all youth, and as such, counselors can work to fulfill the mandate to be social justice activists.

\section{References}

American Psychiatric Association (2000). Diagnostic and statistical manual of mental disorders (Revised $4^{\text {th }}$ edition). Washington, DC: Author.

Austin, L. (2005). Unlocking mental health services for youth in care. Children's Voice. Washington, DC: Child Welfare League of America.

Beck, A.T., Steer, F. A. \& Brown, G.K. (1996). Manual for the Beck Depression Inventory II. San Antonio, TX: Psychological Corporation.

Birhmaher, B., Brent, D. A., Kolko, D. J., Baugher, M., Bridge, J., Iyengar, S., Ullon, R. E. (2001). Clinical outcome after short-term psychotherapy adolescents with major depressive disorder. Archives of General Psychiatry, 57, 29-36.

Child Welfare League of America (2005). CWLA standards of excellence in transition, independent living and self-sufficiency services. Washington, DC: Author.

Ellis, A. (2000). Rational emotive behavior therapy. In R.J. Corsini \& D. Wedding (Eds.), Current psychotherapies ( $7^{\text {th }}$ ed), (pp. 166-201). Belmont, CA: Brooks/Cole.

Garber, J. \& Flynn, C. (2001). Predictors of depressive cognitions in young adolescents. Cognitive Therapy and Research, 25, 353-376. 
Garber, J., Clarke, G., \& Weersing, V. R., (2009). Prevention of depression in at-risk adolescents: A randomized controlled trail. Journal of the American Medical Association, 301, 2215-2224.

Gillham, J. E., Reivich, L. H., Jaycox, K. J., Seligman, M. E. P., \& Silver, T. (1990). The Penn Resiliency Program. Philadelphia, PA: University of Pennsylvania.

Gillham, J. E., Brunwasser, S. M., \& Freres, D. R. (2008). Preventing depression in early adolescence. In J. R. Z. Abela and B. L. Hankin (Eds.) Handbook of depression in early adolescence, (pp. 309-322). New York: Guilford Press.

Gillham, J. E., Hamilton, J., Freres, D. R., Patton, K., \& Gallop, R., (2006). Preventing depression among early adolescents in the primary care setting: a randomized controlled study of the Penn Resiliency Program. Journal of Abnormal Child Psychology, 34, 203-219.

Gladstone, T. R. G., \& Beardslee, W. R. (2009). The prevention of depression in children and adolescents: A review. The Canadian Journal of Psychiatry, 54, 212-221.

Harkness, K. C., Bruce, A. E., \& Lumley, M. N. (2006). The role of childhood abuse and neglect in the sensitization to stressful life events in adolescent depression. Journal of Abnormal Psychology, 115, 730-741.

Jackson, B., \& Lurie, S. (2006). Adolescent depression: Challenges and opportunities. A review and current recommendations for clinical practice. Advances in Pediatrics, 53, 111-116.

Kochanek, K. D., Murphy, S. L., Anderson, R. N., Scott, C. Deaths: Final data for 2002. National Vital Statistics Reports; 53, 1-116. Hyattsville, MD: National Center for Health Statistics, 2004.

Monroe, S. M. \& Harkness, K. L. (2005). Life stress, the "kindling" hypothesis, and the recurrence of depression: Considerations from a life stress perspective. Psychological Review, 112, 417-445.

Mufson, L., Dorta, K. P., Wickramarante, P., Nomura, Y., Olfson, M., \& Weissman, M. M. (2004). A randomized effectiveness trial of interpersonal psychotherapy for depressed adolescents. Archives of General Psychiatry, 61 (6), 577-584.

Office of Applied Studies. (2005). Results from the 2004 National Survey on Drug Use and Health: National findings. Rockville, MD: Substance Abuse and Mental Health Services Administration.

Skowyra, K. \& Cocozza, J. (2006). Blueprint for change: A comprehensive model for identification and treatment of youth with mental health needs in contact with the juvenile justice system. Office of Justice Programs, Office of Juvenile Justice and Delinquency Prevention. 
Spence, S. H., Sheffield, J. K., \& Donovan, C. L. (2005). Long-term outcome of a school-based universal approach to prevention of depression in adolescents. Journal of Consulting and Clinical Psychology, 73, 160-167.

Vernon, A. (2006). Thinking, feeling, behaving: An emotional education curriculum for adolescents $\left(2^{\text {nd }}\right.$ ed.). Champaign, IL: Research Press. Basic Books.

Young, J. F., Mufson, L., \& Davies, M. (2006). Efficacy of interpersonal psychotherapy adolescent skills training: An indicated preventive intervention for depression. Journal of Child Psychology and Psychiatry, 47, 1254-1262.

Zalsman G, Brent DA, Weersing VR. (2006). Depressive disorders in childhood and adolescence: an overview. Epidemiology, clinical manifestation and risk factors. Child and Adolescent Psychiatric Clinics of North America, 15, 827841.

\section{Author Note}

Funding for this study was jointly provided by Blue Cross Blue Shield of Michigan and Spectrum Human Services, Inc. \& Affiliated Companies, and both organizations have the authors' appreciation for this support. Inquiries regarding this article should be directed to Nancy G. Calley, Associate Professor and Chair, Department of Counseling and Addiction Studies, University of Detroit Mercy, calleyng@udmercy.edu. 
Figure 1

My Safety Plan

The purpose of this exercise is to identify the types of activities you can do when you are not feeling in control of your feelings and who can help you during this time.

\begin{tabular}{|l|l|}
\hline Activity: & Who/What/Location or Telephone \#: \\
\hline Do Depression Checklist & ME \\
\hline Who can I talk to that cares about me? & \\
\hline Who can check in with me or be with me & \\
\hline What professionals can I talk to? & \\
(teacher, school counselor, worker, ther- & \\
\hline $\begin{array}{l}\text { How can I check the role that my } \\
\text { thought/beliefs are having on my feeling/ }\end{array}$ & \\
\hline What kinds of things can I do that usually & \\
\hline Where can I go for help (community re- & \\
\hline Who can I ask to help me access re- & \\
\hline Is there anything else that I need to know & \\
\hline
\end{tabular}

